\title{
The effect of temperature and rainfall on psychiatric inpatients'
} admissions

\author{
Athanasios Tselebis*1, Georgios Moussas ${ }^{2}$, Argiro Pachi ${ }^{1}$, Kalliopi Vassila- \\ Demi $^{1}$, Dionisios Bratis ${ }^{1}$, Ioannis Ilias ${ }^{3}$, Georgios Gournas ${ }^{1}$ and \\ Athanasios Karkanias ${ }^{1}$
}

\begin{abstract}
Address: ${ }^{1}$ Psychiatric Department, Sotiria General Hospital, Athens, Greece, ${ }^{2}$ Second Psychiatric Department, Attikon General Hospital, University of Athens, Greece and ${ }^{3}$ Elena Venizelou General Hospital, Athens, Greece

* Corresponding author
\end{abstract}

\author{
from International Society on Brain and Behaviour: 3rd International Congress on Brain and Behaviour \\ Thessaloniki, Greece. 28 November - 2 December 2007 \\ Published: 17 April 2008 \\ Annals of General Psychiatry 2008, 7(Suppl I):S20I doi:I0.1 I86/I744-859X-7-SI-S20I
}

This abstract is available from: http://www.annals-general-psychiatry.com/content/7/SI/S20 I

(c) 2008 Tselebis et al.; licensee BioMed Central Ltd.

\section{Background}

The effect of weather conditions on the need to admit patients in psychiatric wards has been studied; more particularly this effect has been focused on the influence of exposure to sunlight and ambient temperature. Relative atmospheric humidity and rainfall may influence medical admissions. Thus, the aim of the present study was to assess the effect of ambient temperature and rainfall on Greek inpatients' psychiatric admissions.

\section{Materials and methods}

We included all the Greek inpatients' admissions in a general hospital's psychiatric ward over four years. Gender and age for each inpatient, as well as the discharge diagnosis (per DSM - IV - TR) and the admissions' particular conditions (voluntary or involuntary) were noted. Regarding environmental conditions the average peak monthly ambient air temperature and cumulative monthly rainfall in the greater Athens area during the study period (as provided by the Greek Meteorology Authority) were noted. Gender, age, diagnosis and the admission conditions were assessed vis--vis environmental conditions with Pearson's correlation.

\section{Results}

One thousand three hundred and seventy six inpatients (men 50.5\% \& women $49.5 \%$ ) were included in the study. Mean age was $41.6 \pm 14.2$ years (men $40.4 \pm 14.1$ \& women $42.7 \pm 14.3$ years). Seventy five percent of admissions $(n=1031)$ were voluntary and $25 \%(n=345)$ were involuntary.

Temperature was strongly positively correlated with the number of overall psychiatric admissions ( $\mathrm{r}=0.475$, $\mathrm{p}<0.01)$, admissions for schizophrenia and other psychoses $(r=0.360, p<0.01)$ and with male gender of admitted psychiatric inpatients $(\mathrm{r}=0.416, \mathrm{p}<0.01)$. A positive correlation was noted between temperature and the number of involuntary admissions $(\mathrm{r}=0.302, \mathrm{p}<0.05)$, whereas the correlation between temperature and the number of inpatients admitted because of mood disorders was of marginal statistical significance $(\mathrm{r}=0.260, \mathrm{p}=0.05)$. Rainfall was negatively correlated with overall psychiatric admissions $(\mathrm{r}=-0.306, \mathrm{p}<0.05)$. Further negative correlations of rainfall were also found with the number of patients admitted for organic brain syndrome $(\mathrm{r}=-0.373, \mathrm{p}<0.01)$ and involuntary admissions $(\mathrm{r}=-0.425, \mathrm{p}<0.01)$.

\section{Conclusions}

It appears that temperature may influence the number of psychiatric inpatients' admissions. This may be attributed to the unfounded and no-so-uncommon practice of giving lower drug dosages during periods of high ambient temperature or heat waves (nevertheless this treatment change remains to be substantiated by "hard" clinical evidence). Furthermore, the negative effect of rainfall on psy- 
chiatric admissions may be attributed to limited health care accessibility at times of precipitation.

Publish with Bio Med Central and every scientist can read your work free of charge

"BioMed Central will be the most significant development for disseminating the results of biomedical research in our lifetime. " Sir Paul Nurse, Cancer Research UK

Your research papers will be:

- available free of charge to the entire biomedical community

- peer reviewed and published immediately upon acceptance

- cited in PubMed and archived on PubMed Central

- yours - you keep the copyright 